\title{
ARTE Y DUELO: \\ PROCESO DE EMANCIPACIÓN UN CASO: \\ EL FLAMENCO
}

\author{
ART AND GRIEF: EMANCIPATION PROCESS. A CASE STUDY: THE FLAMENCO
}

ARTE E LUTO: PROCESSO DE EMANCIPAÇÃO. UM CASO: O FLAMENCO

180

Por

\section{Alejandra Toro}

Profesora de la Escuela de Comunicación Social Universidad del Valle ${ }^{1}$

alejandra.toro.calonjea@correounivalle.edu.co

Resumen: En este artículo, derivado de una investigación adelantada en el marco de un doctorado sobre Arte y Conflicto, se adelantará en una primera etapa una reflexión genérica en torno a las relaciones entre el arte y el duelo, inscritas en el marco de un proceso de paz. Las víctimas sobrevivientes de un conflicto requieren hacer el duelo para aceptar la reconciliación con quienes fueron sus victimarios. En ese proceso de duelo, el papel del arte es fundamental.Y a manera de estudio de caso, se expondrá la historia de los gitanos andaluces y el flamenco, en el que éste será considerado como un proceso vital para la construcción de la paz, como la manifestación pacífica gitana ante la injusticia.

Palabras clave: Arte, Duelo, Verdad, Paz, Reconciliación, Conflicto, Gitanos, Flamenco, Quejío, Duende. 
Abstract: This paper, which derives from a research carried out in a $\mathrm{PhD}$ in Art and Conflict, reflects on the relations between art and grief that take place in a peace process. Surviving victims of a given conflict require to go through a grief in order to accept a reconciliation with their offenders. In this process of grief, art plays a fundamental role. The history of Andalusians and flamenco will be the case study, in which it is considered as a vital process to peacebuilding, and as a peaceful gypsy manifestation to injustice.

Keywords: Art, Grief, Peace, Reconciliation, Conflict, Gypsies, Flamenco, Quejío, Duende.

Resumo: Neste artigo, derivado de uma pesquisa no marco de um doutorado sobre Arte e Conflito, vai se refletir sobre as relações entre a arte e o luto, as quais estão dentro de um processo de paz. As vítimas de um conflito precisam do luto para aceitar a reconciliação com os seus vitimários. Neste processo de luto, o papel da arte é fundamental. Como estudo de caso, vai se expor a história dos ciganos andaluzes e o flamenco, o qual será considerado como um processo vital para a construção da paz, como a manifestação pacífica cigana ante a injustiça.

Palavras-chave: Arte, luto, verdade, paz, reconciliação, conflito, ciganos, flamenco, Quejío, Duende.

\section{Preliminares}

Este artículo se desprende de una investigación que la autora adelanta sobre las relaciones entre el arte (con énfasis particular en la danza) y el duelo emocional en el marco de un proceso social de paz y reconciliación. Damos por entendido que al hablar de danza estamos pensando en el cuerpo como un conjunto de comunicación, pues éste se expresa, como cualquier lenguaje, a través de un habla particular. El cuerpo es una lengua, la danza una de sus hablas. El cuerpo habla a través de la danza. Es, a justo título, un universo enteramente propio, como lo verbal, lo gestual, lo icónico... como cualquier sistema significante. Tiene su identidad, mantiene su autonomía relativa. Se trata entonces, también, de una reflexión que cruza transversalmente el campo comunicacional.

El desarrollo de la investigación doctoral en la cual se inscribe el presente artículo contempla un análisis de cinco casos representativos en los cuales la danza ha sido fundamental para adelantar el duelo en grupos humanos específicos: así, se evoca en ella al flamenco, a través del cual los gitanos andaluces expresan su desarraigo y su quejío; a las danzas y cantos del currulao, donde los descendientes de los esclavos del Pacífico colombiano encuentran una expresión de su rebelión; a la danza africana, expresión artística híbrida desarrollada por los inmigrantes africanos residentes en Francia, que tratan de resolver su problema de identidad y de reconocimiento; a las inquietudes sobre la vejez del cuerpo de la bailarina expresadas por la coreógrafa 
española Teresa Nieto en su propuesta de danza contemporánea; a la contundencia de la obra de la coreógrafa alemana Pina Bausch, que explora la fragilidad femenina y su lucha incansable por encontrar un espacio digno en la sociedad; y finalmente a las danzas japonesas Butoh, donde aquellos seres que sobrevivieron atónitos a los estragos de la bomba atómica de Hiroshima vertieron todo su dolor. A algunos de ellos se hará referencia tangencial en el presente artículo $^{2}$, pero se abordará plenamente el flamenco pues reúne, a la altura del avance de la investigación, elementos suficientes para entender el proceso a través del cual el duelo se transmuta en una obra de arte y sirve, junto a otros factores de diversa naturaleza, para que la población concernida (en este caso los gitanos) alcance niveles de emancipación social.

\section{El camino hacia la reconciliación}

La hipótesis central del trabajo es la siguiente: el arte (y cualquiera de sus expresiones, en nuestro caso la danza) media, junto con otros factores, entre las víctimas de un conflicto y la sociedad en donde éste ocurre creando las condiciones necesarias para que las víctimas sobrevivientes elaboren el duelo, requisito indispensable para la reconciliación. Dicho de otra manera, el arte puede constituirse en un elemento esencial en un proceso de construcción de paz, ayudando a elaborar y a sobrellevar el dolor de los sobrevivientes. Si se requiere la convergencia plena de una serie de requerimientos para formalizar la paz (verdad, justicia, reparación y garantía de no repetición), el proceso de adaptación emocional de los sobrevivientes no puede ser completo si en particular una de estas exigencias no se da a plenitud: hablamos de la verdad -condición sine que non para que las víctimas sobrevivientes superen su pérdida-. Para ilustrar nuestro argumento, en las condiciones actuales de Colombia, no podemos ignorar como trasfondo particular el proceso de paz que el actual gobierno adelanta con las Farc, principal organización insurgente ${ }^{3}$.

En otras palabras, no hay paz sin duelo, como tampoco duelo sin verdad. Podría agregarse un último paso: la memoria, como base indispensable para obtener la verdad. Estos enunciados establecen entre sí una red de interdependencia solidaria: la memoria permite la verdad, la verdad permite el duelo, el duelo permite la paz. Roto alguno de estos eslabones, la paz conseguida, finalidad última de los procesos de reconciliación, será inacabada, lo que puede dar lugar a contradicciones posteriores en la consolidación del proceso de paz.

El duelo es, pues, el elemento indispensable para que las víctimas puedan reconciliarse con sus propios fantasmas. Y si de entrada hacemos tanto énfasis en el duelo, se debe a que es sólo durante el proceso de su elaboración que las víctimas sobrevivientes estarán en capacidad de empoderarse (es decir, de asumirse) y luego, eventualmente, de transmutar sus sentimientos y su percepción en una obra de arte (personalmente o por mediación de artistas). Sin duelo no hay avance personal en la capacidad de coexistir con los recuerdos tormentosos de las víctimas sobrevivientes ni, -qué decir-, con los victimarios o con la sociedad de la que son oriundos. 
Para entender mejor la argumentación que se está exponiendo, conviene precisar el concepto de víctima, pues finalmente todo lo dicho a propósito de un proceso de paz sólo tiene sentido si está referido a las personas que han sufrido la violencia.

Proponemos una serie de categorías de víctimas para reconocer la diferencia que se comprueba en la realidad, lo que conlleva también a afinar el concepto de desaparecido. Debemos advertir que estas categorías no se encuentran nítidamente separadas en la realidad: es una construcción conceptual. En algunos casos hay rasgos propios de dos categorías que se superponen o se traslapan.

Hay que distinguir entonces a la víctima inmediata (el asesinado, muchas veces también desaparecido) de sus sobrevivientes -familiares, allegados, miembros de su entorno afectivo-. Son víctimas ambas, pero su naturaleza es distinta.

Por otra parte, la acepción primera de "desaparecido" alude a aquel cuyo paradero se desconoce, aquel que se desvaneció sin dejar rastro alguno. Nuestra idea de "desaparecido" se limita, sin embargo, al llamado "desaparecido forzoso", es decir, no aquel perdido por voluntad propia sino, por el contrario, el que ha sido desaparecido por fuerzas que le son externas: agentes del Estado, paramilitares, guerrilla. En muchas ocasiones, aquellos que han sufrido de desaparición forzada (en particular en el proceso colombiano) han sido desmembrados por los asesinos y sus partes dispersadas para ocultar por completo el cuerpo y la prueba de la violencia padecida.

Ahora bien, si desaparecer consiste también en dejar de existir, se puede afirmar que las víctimas sobrevivientes, en la medida en que tienden a ser "borradas" socialmente (por menosprecio, por indiferencia, por desatención), sufren igualmente un proceso que bien podría ser calificado de desaparición. De una manera diferente a la de los otros desaparecidos, claro, pero no menos real. Estas víctimas borradas o invisibilizadas constituyen una nueva categoría, distinta a la víctima primigenia y a la víctima sobreviviente, y en todo caso una evolución de la segunda. Existe, sí, sobrevive, sí, pero su existencia es inocua, intrascendente, pasa desapercibida, tal y como ocurre con las poblaciones migrantes de refugiados (como los gitanos, por ejemplo, los sirios en la actualidad, los amplios grupos de personas de la costa Pacífica colombiana), que han visto interrumpidos el sentido de sus vidas y su identidad como seres humanos, obligadas a dejar sus territorios de vida y de implante cultural. Ellas deambulan por las fronteras de los países o por las calles de las grandes ciudades viviendo en condiciones infrahumanas y sin reconocimiento estatal: las estadísticas apenas las mencionan. Han desaparecido del espectro social. Estos ignorados por las instituciones y por el poder, si bien no han fallecido físicamente aunque no tengan (supongamos) familiares muertos o desplazados, también deben ser considerados víctimas del conflicto; no han desaparecido materialmente pero el poder, como dice Foucault, los ha moldeado hasta hacerlos inocuos. 
Una última categoría de víctimas podría estar constituida por todos aquellos que se van desgastando en la búsqueda infructuosa de sus familiares desaparecidos. Van perdiendo su corporalidad, su fuerza, su salud física y mental. De tanto buscar ya no les queda aliento, ni cuerpo, ni voluntad. Como consecuencia de este trajín, se van deshilachando en el tiempo y en el espacio. Esta negación puede llegar a convertirse, en estas víctimas, en una auto-negación: la persona se enferma, calla, deja de considerarse un ser social con capacidad de intervención. Muere, metafóricamente, y, en algunos casos, físicamente. Se marchita. De cierta forma, esta última categoría es una evolución todavía más degradada emocionalmente de la víctima sobreviviente y de la víctima invisibilizada.

Así pues proponemos cuatro categorías de víctimas para nuestro análisis: la víctima primera; la víctima sobreviviente; la víctima desplazada, y, por último, la víctima borrada. Muchas de ellas siguen vivas y su existencia está marcada por la búsqueda del familiar desaparecido, la víctima primera. Es su empeño fundamental. El hallazgo del cuerpo - o en su defecto, de lo que queda de él- es un momento trascendente pues, cuando ello ocurre, se admite implícitamente que el ser querido ha muerto de verdad. Pero encontrarlo conlleva asimismo un gran alivio porque la víctima sobreviviente comienza a despejar la incertidumbre que lo ha venido acongojando. La búsqueda al fin terminó. Solo ahí se puede

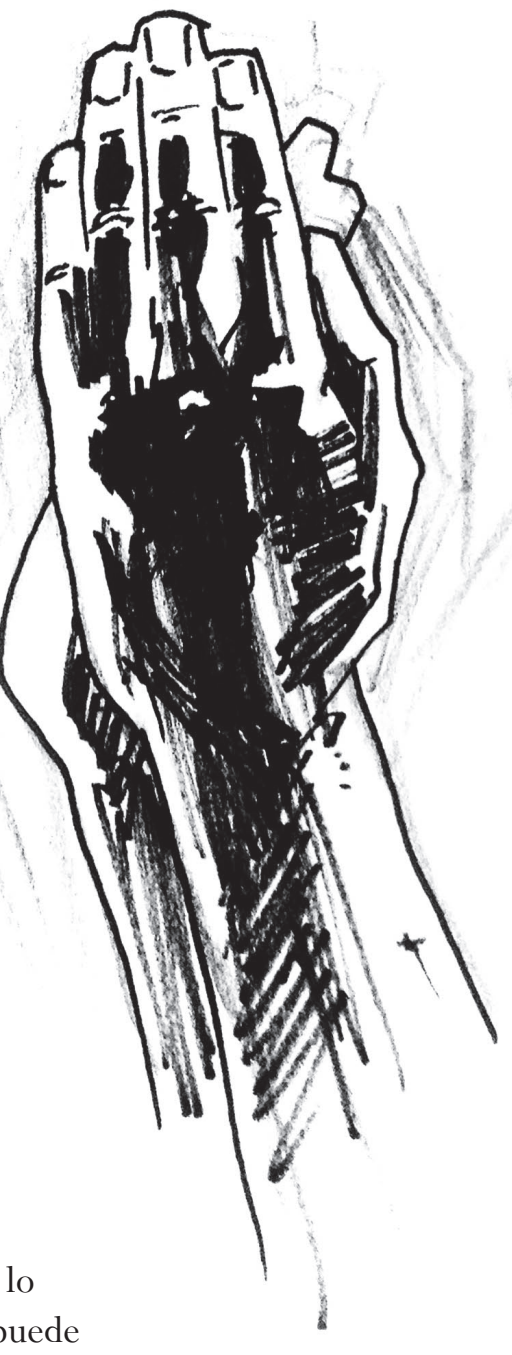
iniciar el verdadero duelo. Es un quiebre tremendo en los procesos personales de reconstrucción. Sin ese hallazgo fundamental no hay duelo que pueda empezar.

\section{El arte: los cuerpos empoderados y transmutados}

Ahora bien, cuando el cuerpo de la víctima inicial no ha podido ser recuperado físicamente, los sobrevivientes pueden acudir a otras formas de recuperación, en este caso de carácter simbólico. Históricamente, el proceso de duelo de las víctimas sobrevivientes se materializa a través de monumentos, memoriales, museos, lápidas, cenotafios y sepulturas ${ }^{4}$. Estos espacios "tienen en común su propósito confesado de formar voces alternativas de resistencia a la dominación y a las voces dominantes de la violencia" (Ramsbotham, Miall, Woodhouse, 2011, p. 348) $)^{5}$. 
Los procesos simbólicos también se expresan a través de obras de arte. Muchos ejemplos podrían ser citados: Guernica, de Pablo Picasso, es quizás la obra contemporánea más emblemática. Este cuadro representa el dolor humano y los muertos y desaparecidos por los bombardeos sobre la población española homónima al inicio de la Segunda Guerra Mundial. El Guernica recupera simbólicamente a las víctimas de esa población. Rescata los muertos a través de símbolos: un toro agonizante, un cuerpo destrozado por las llamas, la oscuridad que se percibe en ese refugio atiborrado que solo ilumina un bombillo... Los muertos del cuadro son representados a través del lenguaje propio de la pintura -un lenguaje altamente simbólico, como todo lenguaje artístico-. Para las víctimas sobrevivientes de los bombardeos y para sus descendientes, en el Guernica de Picasso están presentes simbólicamente sus muertos. Razonamiento semejante se podría hacer a propósito de la serie de Goya Los desastres de la guerra, de las pinturas de Fernando Botero sobre las víctimas de tortura en la prisión iraquí de Abu Ghraib, de El Partenón, en Atenas, de los murales de Diego Rivera en México, de la obra de la artista plástica Doris Salcedo y de ciertas coreografías de danza contemporánea de El Colegio del cuerpo, de Álvaro Restrepo, para citar sólo algunos ejemplos. En ese proceso, en el que intervienen muchos determinantes, el arte transmuta la memoria y la experiencia de los dolientes en expresiones artísticas, es decir, en lenguajes que, si bien parten de la realidad cruda de las víctimas, se distancian de ella (la realidad) al ser dotado el lenguaje artístico de elementos simbólicos y abstractos, propios de su naturaleza discursiva. La obra de arte no asume a las víctimas primeras de forma rigurosamente referencial ${ }^{6}$. No, la obra de arte procede utilizando las herramientas y el lenguaje que le son propios: metáforas, figuras retóricas, símbolos, abstracciones, representaciones. Estas últimas difieren en función de la naturaleza de la obra en que se materializan: una pintura, una escultura, una obra de teatro, una novela, una pieza de danza contemporánea... Una obra de arte es una representación: el artista re-presenta -vuelve a presentar- una realidad que le ha sido mostrada, contada o que ha vivido. El discurso de la víctima sobreviviente (individual en unos casos, colectiva en otros) se transmuta en una obra de arte gracias a la mediación efectuada por la obra misma. El lenguaje del arte no es un calco de la víctima sobreviviente, pues hay una trasmutación que realiza el artista, aun en el caso extremo en que elementos del discurso de la víctima sobreviviente sean integrados tal cual en el discurso artístico ya que, al ser insertados y moverse entonces en nuevas relaciones intra-textuales, adquieren un valor distinto, estético, artístico.

\section{El pueblo gitano andaluz}

Una guitarra dulce. Los dedos acarician rápido las cuerdas. Sonidos torbellinos y metálicos, acordes tristes que se pierden en los valles de olivos y naranjos en flor. Las palmas marcan ya el ritmo, pero aún siguen tímidas. Una voz, afilada, adolorida, potente, desgarra el ambiente. “¡Olé!”, murmura el público para darle la bienvenida al cantaor. La bailaora, con su moño apretado y su falda de lunares, inicia un movimiento de brazos y cabeza, su tronco se arquea, las manos giran desde la muñeca en suaves torsiones que acentúan aún más la línea expresiva de los brazos. Los pies marcan suavemente. La espalda está erguida, la cabeza es desafiante, la mirada se hace fuego. 
Garbo y gracia, dedos de mariposas, demonio y sensualidad.

Arranca un zapateado endiablado, marcando con precisión una cadencia veloz. Las palmas siguen otro ritmo. Su rostro es dolor puro. El cantaor cierra los ojos. Tiembla. El guitarrista tiene los dedos en fuego. El quejío está en todas partes. Palpitante, sobrio, terrible, abrasador, el flamenco es también expresión de nostalgia, de pena, de ternura. Pero al final, el flamenco es siempre una fiesta, de alegría, de emoción, para celebrar la vida misma.

Trataremos ahora, como he anunciado, de ilustrar los conceptos propuestos en la primera parte de este ensayo con un caso particular: el del flamenco, expresión artística del pueblo gitano andaluz.

Iniciaremos dando la definición de "gitano" del Diccionario de la Real Academia Española:

Gitano, na: (De egiptano, porque se creyó que procedían de Egipto).1. adj. Se dice de los individuos de un pueblo originario de la India, extendido por diversos países, que mantienen en gran parte un nomadismo y han conservado rasgos físicos y culturales propios. 2. adj. Propio de los gitanos, o parecido a ellos. 3. adj. Que tiene gracia y arte para ganarse las voluntades de otros, más como elogio, y especialmente referido a una mujer. 4. adj. coloq. Que estafa u obra con engaño ${ }^{7}$.

Ya desde el lenguaje se marcan los cuerpos. Ya desde los discursos hegemónicos enunciados por los detentores del poder, se discriminan los sujetos. Veremos cómo el cuerpo de los gitanos ha sufrido -y sigue sufriendo-, otras numerosas segregaciones.

Los primeros datos sobre la migración gitana en Europa se sitúan a partir de 1415. Antes del siglo $\mathrm{XV}$, se citan algunas fuentes que refieren a pequeños grupos vagando por los Balcanes, pero sin certeza de que fueran realmente gitanos. Aunque es imposible determinar con precisión el origen del pueblo gitano, una de las hipótesis más desarrolladas afirma que un importante movimiento migratorio se generó en la India a principios del siglo XV. Varios cronistas describieron a pobladores de este país con rasgos similares a los hombres y mujeres que migraron a Europa. Entre todos destaca la comunidad de los tzengaris, (que se acerca al término “cíngaros” en español), una casta originaria de la costa Malabar (suroeste de la península de la India). Cuentan que vagaban nómadas en grupo en busca de mejores condiciones de vida entre las ciudades del suroeste de la India. Eran de color negro cobrizo, errantes, adoraban a la diosa Kali y se dispersaban por el mundo. 
Los gitanos prolongaron su transitar por Asia Central durante varios siglos: cruzaron Pakistán, Afganistán, Uzbekistán, y llegaron hasta el mar de Aral. De ahí cruzaron a Turquía, rumbo a otros destinos como Rusia, Rumania y República Checa. En su deambular por Europa oriental, los gitanos fueron esclavizados y perseguidos por los tártaros. Su profundo conocimiento de los caballos permitió que fuesen empleados en labores de retaguardia tales como herreros, fabricantes de arreos y de elementos de carga. Otros oficios que ocuparon estuvieron siempre en relación con la caballería, como el domado y cuidado de las bestias; eran expertos en la fragua, trabajaban en la fabricación del armamento o en la reparación de ollas de cobre. Trabajaban el cuero o se desempeñaban como músicos y bailarines que divertían a la tropa. Los hindúes, antepasados de los gitanos, constituyeron así un número considerable de "personas con piel de color del cuero envejecido", como dice Manuel Piñar, que deambulaban y acompañaban al ejército, vivían fuera de la ciudad y comerciaban con la tropa (Piñar, 2012, p. 38). Las mujeres decían la buenaventura a cambio de dinero, al tiempo que tocaban el pandero y vendían amuletos.

Otra hipótesis, más discutida, afirma que hubo una penetración por el norte de África. Manuel Piñar evoca textos de cuatrocientos años atrás que refieren a los gitanos como originarios del Klein Gypten, pequeño Egipto, o en otras palabras, Egipto menor. De ahí su nombre, Egipcianos, léxico que derivó finalmente en "gitanos".

La primera referencia histórica que se tiene de la presencia de los gitanos en España es de enero del año 1425 (Piñar, 2012, p. 73). El gitano encontró en Andalucía su lugar predilecto para establecerse. Ya en el siglo XVI, España era un país despoblado por la emigración a América y la expulsión morisca, que necesitaba mano de obra para la dura labor del campo. Los gitanos hallaron pues las condiciones ideales para su asentamiento.

Fuentes históricas apuntan que algunos clanes de gitanos se estabilizaron en torno a puestos de trabajo tradicionales como las fraguas o las carnicerías. Otros, sin embargo, se dieron a deambular y a la rapiña y, con el tiempo, cualquier acto de hurto no aclarado se les atribuía, aunque lo hubiesen cometido personas ajenas a su comunidad. Por otra parte, los gitanos eran dados a la magia negra, hechizos y adivinanzas y a la celebración de ritos no católicos.

Fueron estos los elementos que con el tiempo dieron lugar a que se considerasen "gitanos" a todos los que deambulaban y no estaban asentados y se les catalogase como elementos peligrosos. Conforme continuaban su migración hacia el oeste, los gitanos fueron sistemáticamente condenados a las galeras, en Francia en particular. Creció el rechazo general en el resto de Europa y en España, fueron proclamados edictos que prohibían el matrimonio entre miembros de su comunidad para "purificarla", y leyes que les perseguían y buscaban su expulsión y expropiación de sus tierras. Los Reyes Católicos, con la oportuna intervención de la Inquisición, fueron sus implacables perseguidores, al igual que de los moros y judíos sefardíes. Eran acosados por su condición racial y víctimas de una religión dominante que no admitía su singularidad. 
En el reinado de Felipe IV surgió la legislación más dura contra los gitanos, con la Pragmática de 1633 donde se estipulaba que:

Los que se llaman Gitanos, salgan fuera del Reyno, y que no se vuelcan a él, so pena de muerte: $y$ los que quisieren quedarse, avecinándose en un lugar de mil vezino arriba, y que no usen el traje, lengua y nombre de gitanos... so pena de muerte. (...) Se veda (...) que use su lengua, y los oficios que les están prohibidos, y anden en ferias... y que hagan juntas en público, ni en secreto, so pena de doscientos açotes y seis años de galeras, (...) con mujeres, con destierro... que no se llamen ni otros los llamen Gitanos, y que ni en danças ni de otro accto se permita represetacino, acción (...), pena de dos años de destierro y cincuenta mil marauedi.(Piñar, 2012, p. 152)

Como se ve, la prohibición se orientó a todos los elementos distintivos del gitano, incluido el nombre, las danzas o cultura. Fueron reducidos a las llamadas "gitanerías" establecidas en barrios de ciertas ciudades del sur del país: Triana, en Sevilla, El Sacromonte granadino, Santiago de Jerez y otros, auténticos guetos de los que no se les estaba permitido salir después de la puesta del sol, so pena de graves castigos, donde lo que se pretendía era sedentarizarlos y asimilarlos.

Estamos ante verdaderas políticas de exterminio, que tiene uno de sus paradigmas en la Gran redada de 1749, un plan secreto del rey Fernando VI donde se perseguía arrestar y extinguir a todos los gitanos del reino, ya fuera mandándolos a la cárcel, a las galeras o a través de su física aniquilación. Se estima que entre 8000 y 12000 gitanos y gitanas fueron arrestados, con la plena colaboración de las autoridades eclesiásticas, policiales y civiles.

Como reacción a las leyes segregacionistas, los gitanos debieron mantenerse ocultos. Al igual que los judíos, debieron borrar sus orígenes para integrarse a la sociedad española, convirtiéndose al catolicismo y adoptando nombres y apellidos que los hicieran pasar desapercibidos. Sus celebraciones públicas, cantes y bailes, fueron censurados hasta convertirse en un tabú para muchos de ellos. Así, entre los flamencólogos, se admite la existencia de un cante y baile limitados y, en cierto modo, ocultos, de uso y exhibición estricta a los ámbitos privados. Aun hoy, se celebran en las bodas gitanas, en círculos estrictamente familiares, cantos y bailes originarios de la India y de su folklore tradicional que solo unos pocos privilegiados pueden observar. Reservan pues otro flamenco a sus reuniones más íntimas, cuando tienen la seguridad de que ningún extraño se halla presente. En otras palabras, los "payos", término -hay que decirlo-, no desprovisto de cierto desprecio bajo el cual nombran a quienes no son de su raza, no presencian sino en contadas ocasiones la esencia más tradicional del flamenco.

Así describe Jan Yoors, un artista y fotógrafo belga que vivió con una kumpanía romaní desde los doce años y fue adoptado por una familia gitana, una celebración que presenció durante sus largos años de permanencia en la comunidad. Los gitanos, dice el entonces joven payo, empezaron a entonar una pieza de baile gitana, 
También a cantar y a dar palmadas. Secundaban el ritmo con los pies hasta que uno de ellos, más impaciente que los demás, se metió de un salto en el pequeño espacio abierto y empezó a bailar. Golpeaba el suelo con pasos contundentes y mantenía una expresión facial extrañamente contradictoria y desenfadada, con un deje de ironía socarrona en los ojos. Sus brazos y su torso se movían con gestos lentos y elegantes. Las palabras improvisadas de la canción transmitían alegría y humor. Los taconazos en el suelo se hicieron más fuertes y vigorosos. Otro chico se unió a él con movimientos frenéticos. Los espectadores estaban de un humor excelente. (...). Entre ellos todavía perduraba la nostalgia de la vieja canción. (Yoors, 2009, p. 94)

Como ésta, los gitanos crearon otras formas de resistencia, detrás de las que aún se ocultan, implementando prácticas que apuntan a aumentar la desconfianza y el recelo de los payos. Así, con la lectura de la buenaventura, el robo de las posesiones ajenas, actividades aureoladas de superstición y de una inquietante relación con el diablo, crean exiguas pantallas de protección y espejismos que logran engañar y alejar a los payos. De esta manera, evitan una confrontación con el poder, de la cual ya conocen el triste desenlace. Independientes y orgullosos, prefieren que no haya mayor contacto con los que no son como ellos. Hay una manifiesta intención de poner barreras con aquellos con los que no comparten necesariamente ni la cosmogonía, ni la visión del mundo ni las leyes. Los gitanos se borran de la escena de la violencia. Se "auto-desaparecen". Jan Yoors se sorprende de "su incomprensible e inexplicable falta de reacción traumática ante las violentas persecuciones personales que sufrían. (... de) su rechazo del odio o de la amargura personal como formas de responder a las presiones externas" (Yoors, 2009, pp. 11 - 12).

Muchos gitanos viven hoy en España en clanes familiares, en barrios donde los payos no entran, conservando una marcada tradición rural y manteniendo fuertes lazos de cohesión y de lealtad con su propio pueblo. El patriarcado es la línea absoluta de conducta, la figura del padre es omnipotente, el rol de la mujer es esencialmente el de madre. Viven a la orilla de los occidentales, y el flamenco es una de las formas con las que permean ese mundo del cual se auto-excluyen y del cual evidentemente han sido prescindidos.

No es el espacio para desarrollar las actuales condiciones de los gitanos en el mundo. Basta con recordar que los derechos del pueblo romaní se siguen violando constantemente, siguen siendo perseguidos y expulsados manu militari de los terrenos donde acampan. El pueblo gitano sigue padeciendo la homofobia y la xenofobia de un sector de la Europa de ultraderecha que los esclavizó en Rumania hasta el siglo XIX y pretendió exterminarlos -se habla incluso de genocidio- durante la Segunda Guerra Mundial. Los gitanos siguen siendo discriminados por su diferencia, su forma libre de vivir y por su negativa a actuar bajo los códigos occidentales. 


\section{El origen del flamenco}

Retomando nuestra argumentación, cualquiera sea el origen de los gitanos andaluces, ya sea India o Egipto, fueron varias etnias y de procedencias diversas las que se finalmente se asentaron en Europa occidental. Un elemento les unía: la extrema pobreza de estos pueblos nómadas que buscaron acogida en el corazón de Europa. Ambas hipótesis se sustentan en hechos que derivaron en persecuciones, ejecuciones y toda suerte de barbaridades que se cometían en las guerras de la antigüedad. En Alemania, Francia y España se mezclaron las distintas etnias y, con este intercambio, se modificaron profundamente el idioma, las creencias religiosas y tradiciones musicales, la sociedad y cultura gitanas.

Esta primera mezcla de culturas en el seno de la comunidad gitana es fundamental para entender el modo en que surge el llamado "cante gitano" y las influencias que hubo en la formación del flamenco.

Los gitanos llegaron a España bailando desde el primer momento. Fue el elemento genuinamente gitano y de forma indiscutible. Era relevante y notorio el arte de las gitanas en la interpretación de sus danzas; que los bailes los acompasaban con cantes en algunos casos, es cierto, y con palmas y jaleos, pero esos cantes no se relacionan como cantes flamencos hasta entrado el siglo XIX, donde comienzan a aparecer referencias con denominaciones específicas. (Piñar, 2012, p. 108)

Alegría, tango, soleá, seguiriya, fandango, bulería, saeta, farruca son así algunos de los "palos" del flamenco, es decir la forma cómo se denominan las variedades tradicionales del cante y baile. Los palos pueden clasificarse según varios criterios: su compás, su jondura, su carácter serio o festivo, su origen geográfico.

Los primeros cantes con forma flamenca surgieron de los gitanos en las ciudades andaluzas de Sevilla, Cádiz y Jerez hacia 1780. Los primitivos escenarios de entonces eran los bailes de candil en los patios de los vecinos, las trastiendas de las botillerías y las cuevas del Sacromonte granadino.

Una de las mayores influencias que recibe el flamenco es, por obvias razones, la de un folklore local totalmente entintado de arabismos, como consecuencia de siete siglos de dominación musulmana en el al-Ándalus, como se conoce al territorio de la península ibérica bajo el poder musulmán durante la Edad Media, entre los años 711 y 1492.

Sin embargo, el flamenco se nutrió de todas las culturas que se asentaron en Andalucía (andaluces, moros, gitanos, judíos), cada una con su forma de expresar la alegría y el dolor, las tragedias y las celebraciones. 
El cante desde sus orígenes se caracterizó por resaltar vivencias en primera persona y entre ellas se destaca la desazón, la amargura o la impotencia. Desde sus inicios, el poeta "Félix Grande (lo) asocia al lamento de la clase humilde andaluza, impotente frente a la clase poderosa, en la que toman destacado protagonismo, además de los gitanos, bandoleros y moriscos" (Piñar, 2012, p. 103).

El baile fue el que arrastró la incorporación de cantes que lo acompañaran y, posteriormente, la introducción de la música y de la guitarra, un hito fundamental en la historia del flamenco. Bailaores, cantaores y guitarristas, el indispensable trío para el flamenco estaba creado. Todo lo que en el tablao lo acompaña hoy en día constituye el cuadro flamenco: los que dan las palmas, los percusionistas, el decorado, los trajes, los jaleadores.

El baile daba a los gitanos cierto prestigio y por tanto autoestima frente al maltrato secular que venían padeciendo, les acercaba al resto de la sociedad (...) contribuyendo a vencer el prejuicio social de gitano igual a malhechor, y, sobre todo, ofrecía a algunas gitanas la oportunidad de obtener beneficios económicos. Eran aspectos que debieron animar a toda la comunidad gitana circundante a seguir ese camino y predisponer a otros a sacar su cante al público. (Piñar, 2012, p. 107)

Se extrae de esta manera el flamenco de sus círculos gitanos privados familiares para llevarlo a públicos más amplios, lo cual generó mayor aceptación social y admiración, diversificando así mismo tanto el cante como los intérpretes.

\section{El "quejío"}

Con la incorporación de cantes populares del folklore andaluz como el romance, de cantes litúrgicos mozárabes y de la música gitana, se fue forjando el flamenco. Entre creación gitana genuina o producto de la asimilación cultural de todos los grupos étnicos que convivieron en Andalucía, el flamenco es la expresión artísticomusical más clara de esta región. Una región que García Lorca en su "Poema del cante jondo" no duda en calificar como la "Andalucía del llanto" (García Lorca, 1998 , p. 28). Pues hay un elemento distintivo del flamenco, característico tanto del cante como de la expresividad del baile y las cuerdas: el flamenco es la expresión pacífica de un sentimiento profundo, el clamor de un pueblo lastimado, el "quejío" del pueblo gitano, al que García Lorca rinde homenaje en sus oníricos versos. 
Así lo ejemplifica el siguiente poema, "Barrio de Córdoba", que pertenece al "Poema del cante jondo", donde la referencia al pueblo gitano es evidente: "En la casa se defienden/ de las estrellas. La noche se derrumba. Dentro hay una niña muerta/ con una rosa encarnada/ oculta en la cabellera. Seis ruiseñores la lloran/ en la reja. Las gentes van suspirando con las guitarras abiertas"(García Lorca, 1998, p. 28).

Desde la construcción de su gramática musical y desde su misma forma de articulación, el flamenco se puede asemejar en efecto a una lamentación.

Con una reflexión certera, Félix Grande dice que "las raíces del flamenco son demasiado primitivas, en el sentido en que pertenecen a una tensión cultural a la que la inocencia, el terror, la pena, la necesidad se le notan directamente, sin filtros de refinamiento”. Y en consecuencia, su expresión está llena de las formas más primitivas del lenguaje: el grito y la onomatopeya. (...) El flamenco, en su ejecución, participa de las características de la "voz mediterránea”: primero, a nivel de la fonación destaca la fuerza de voz que se asemeja al grito; segundo, a nivel del timbre predomina la nasalización que permite el enriquecimiento armónico del registro sonoro y la aspereza de la voz, su "sonido negro" (...); tercero, a nivel de la ornamentación estamos ante el extensivo uso de las melismas; y cuarto, respecto al registro habría que mencionar el carácter forzado de la voz, siempre a punto del quebramiento. (Piñar, 2012, pp. 12, 28)

El escritor, director de cine y pintor Edgar Neville, amigo de Manuel de Falla y de Federico García Lorca, resaltaba por su parte las temáticas clásicas del cante flamenco:

la madre que se muere en el hospital se repite con frecuencia, o el recuerdo de la madre muerta, sentimiento profundo y que llega con el cantaor a las oscuras raíces del grito. Pero sobre todo, el tema principal del cante es sobre cuestiones de amor, de un amor apasionado y violento (...). El amor fue siempre el tema primero de todos los cantes (...), pero en el flamenco, y sobre todo en el cante jondo, éste ya se sublimiza y se lleva al límite, porque el amor verdadero nunca se pasa, y cuando parece que ya se fue, escuchad: nos queda un rumor dentro como el del mar en las caracolas. (...) Cualquier otro tema se hubiera gastado pronto, pero el amor, a fuerza de ser eterno y a fuerza de ser fugaz, huidizo, es lo que siempre queda, porque es lo que cuenta, en primer término, en la vida espiritual del hombre. (Neville, 2006, p. 35 y 37)

Las vivencias de los gitanos condenados a las minas, a las galeras y al trabajo de la fragua, basadas en sus experiencias personales, constituyeron la otra esencia de las letras flamencas. La violencia y la explotación de un sistema socioeconómico basado en la servidumbre feudal y la esclavitud fueron temas predilectos en los cantes. El gitano usó el romance en primera persona para hablar de sí mismo y no para narrar la gesta de condes, caballeros o de terceros. Cantó lo que sentía, su amargura, su pena, su drama y también su alegría, entusiasmo, jovialidad, en una sociedad marcada por el temor al clero y la represión de la Inquisición. 
El flamenco no fue un espectáculo, ni nació para ser un espectáculo: era la forma de expresión de un pueblo más bien desarticulado, eran los poemas que decían a grito de llanto unos analfabetos que no podían expresarse de otra manera, eran los lamentos de amor de un tosco primitivo que apenas sabe hablar pero que al recibir la herida se expresa de ese modo. ¿Quién podría pensar que ese lamento íntimo, que ese llanto musical, que ese abrirse las carnes para enseñar el corazón, pudiera ser un día, como se dice ahora, taquillero? (Neville, 2006, p. 33).

\section{El "duende" y lo "jondo"}

"Se desata el duende", "Le llegó el duende" o por el contrario, "Esto no tiene duende". Expresiones de esta naturaleza son comunes en el universo del flamenco. Pero, ¿qué es el duende? ¿Acaso no dijo Manuel Torre, reconocido como el mejor seguiriyero de la historia, que "nadie sabe qué es el duende, nadie más que el que lo ha sentío"? (Piñar, 2012, p. 11).

Escribía Federico García Lorca: "La llegada del duende presupone siempre un cambio radical en todas las formas. Sobre planos viejos, da sensaciones de frescura totalmente inéditas, con una calidad de cosa recién creada, de milagro, que llega a producir un entusiasmo casi religioso" (García Lorca, 2010, p. 18).

El duende es un estado emocional, un instante de magia. Es el aura del cantaor, de la bailaora, del guitarrista, es el alma negra del artista. Solo la palabra de Federico García Lorca lo puede expresar con tanta delicadeza:

El duende opera sobre el cuerpo del bailarín como el aire sobre la arena. Convierte con mágico poder una hermosa muchacha en paralítica de la luna, o llena de rubores adolescentes a un viejo roto que pide limosnas por las tiendas de vino; da con una cabellera olor de puerto nocturno y en todo momento opera sobre los brazos, en expresiones que son madre de la danza de todos los tiempos.(García Lorca, 2010, p. 29)

El duende no se repite. El duende es epifanía. Es la expresión de nuestra fragilidad. Es la capacidad para transcender, y desde la genialidad, llegar a un momento sublime. ¿Acaso no era a esto a lo que se refería Manuel Torre, de quien se dice que fue el cantaor gitano con más duende de la historia, cuando dijo que "todo lo que tiene sonidos negros tiene duende”? (García Lorca, 2010, pp. 10,11). Sonidos negros. Quizás sea esta la metáfora que más se aproxima al duende. Pues duende es la inseguridad del artista, el miedo que paraliza, son esos fantasmas que, indolentes e insolentes, asoman su cabeza para burlarse de sus angustias. Es herida que no cierra, es desgarro, es ese dolor íntimo del cantaor que "solo canta a sus amigos, escupiendo sangre" (Neville, 2006, p. 33). Para García Lorca, "el duende no llega si no ve posibilidad de muerte, si no sabe que ha de rondar su casa, si no tiene seguridad que ha de mecer esas ramas que todos llevamos, que no tienen, que no tendrán consuelo" (García Lorca, 2010, p. 26). La verdadera lucha del hombre, escribía el poeta granadino, es con el duende (García Lorca, 2010, p. 13). 
No se ve pero se siente; no se puede invocar, provocar o apresar... pero se huele. El duende es del orden de la percepción. Se contagia al público. El duende es una conversación que se crea en silencio entre el público y el intérprete, entre artistas, cuando el público se entrega al artista y éste a su auditorio. Es una conversación del alma. Si hay encuentro de almas, el duende fluye solo, es una conversación íntima, que se descubre en las letras, los movimientos o las notas del flamenco. El duende es esa conversación en donde no hay palabras sino emociones. Cuando pasa el duende, "el cante queda en el aire ingrávido porque para eso era su alma” (Neville, 2006, p. 34).

"Alguien me dijo que la mirada es eso que hace desaparecer el espacio vacío entre los cuerpos”, (Fernández, 2011, p. 52). Ver es palpar con la mirada, decía Merleau-Ponty (Merleau-Ponty, 1964). Bailar es convertirse en el otro, considera por su parte el filósofo e historiador del arte Didi-Huberman, (2008, p. 27). Creemos que el duende es esa mirada, eso que conecta al artista con el otro, con el espectador conmovido, a través del cuerpo que le permite tocar el mundo. Ese mundo al que se accede mediante la simple percepción se desvela gracias al duende, a la fragilidad. El duende es esa experiencia intuitiva, es la profunda comunión de un artista con su público. Como dice Oscar Córnago:

El contacto con los infiernos nos da la posibilidad no ya de comprender, pero sí de aproximarnos a la comprensión de nuestras vergüenzas, y con ellas a vivir con el pensamiento del dolor, que inevitablemente nos conecta con el mundo en el que vivimos. (Córnago, 2011, p. 16)

Por eso, el duende es la mejor condición para interpretar lo jondo.

Lo jondo es el concepto que describe un resorte que nos mueve, nos remueve y nos conmueve de una manera distinta que ante la contemplación de una obra de arte o la escucha de una sinfonía. Lo jondo tiene que ver con la búsqueda dentro de nosotros mismos de todo lo que es más nuestro, de lo que duele. Se trata de encontrar la belleza en lo oscuro, en lo trágico a través de una tradición que se remonta muchos siglos atrás y pasa por los grandes clásicos griegos hasta Shakespeare o Goya. Lo jondo es una categoría estética que parte de la insegura consciencia humana del yo. Se trata siempre de salir de esa conciencia ética para arrebatarle, en la medida de lo posible, algún protagonismo a la forma, a lo que se ve, al flamenco que se recarga de más ornamentación de la que necesita para decir lo que tiene que decir el hombre. La reivindicación de lo jondo es solo estética y no tiene nada que ver con la tradición ni con la pureza (Martín, 2006, pp. 30-31).

Con el duende se despiertan sensibilidades profundas, tanto para el artista como para quien lo presencia. Se logran subjetivar aquellas historias ocultas, aquella que solo el intérprete conoce y esa otra que solo el espectador revive. Cada uno es partícipe de la magia. "El cante jondo se desarrolla mejor en la intimidad, busca el recogimiento y el silencio y, por supuesto, como en muchas otras manifestaciones artísticas, los momentos de genialidad son totalmente imprevisibles" (Martín, 2006, p. 46). 


\section{La paz}

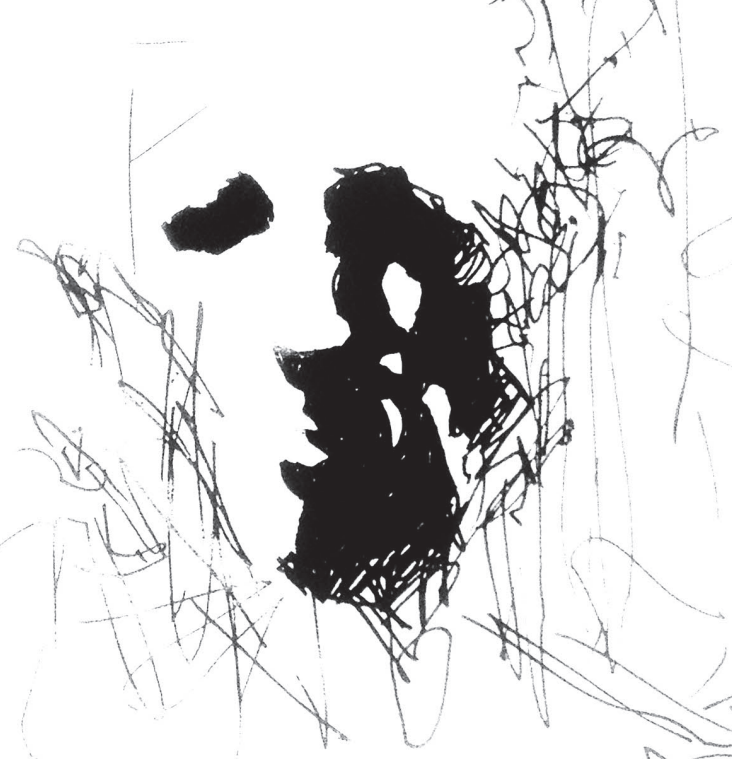

Ya llegando al final de nuestra exposición, expondremos una de nuestras hipótesis fundamentales: la exigencia de memoria planteada por las víctimas (como puede ser el caso de la sociedad colombiana o, en este caso, el pueblo gitano) se afirma en la necesidad ética y política de una apropiación narrativa del pasado de inhumanidad. El flamenco se constituyó de esta manera en un espacio de reivindicación, de subversión, -de desafío si se quiere-, y de resistencia de los gitanos ante los discursos hegemónicos. El quejío, en sí mismo, tiene algo de superación de la pena para las víctimas.

Esto es un claro ejemplo de lo que Michel Foucault define como biopolítica (Foucault, 1981), o el ejercicio del poder y control sobre los cuerpos de los sujetos para hacerlos útiles y obedientes. Según Foucault, el control de la sociedad no sólo se realiza a través de la ideología sino que se requiere del control del cuerpo de los individuos. Por medio del castigo se transforma la vida humana. Por medio de la vigilancia y la interiorización de las estructuras de poder se regula la población.

Sin embargo, ante toda forma de poder se erigen determinadas resistencias. En sus reflexiones sobre biopolítica, Foucault argumenta que el poder circula, no es propiedad exclusiva de unos pocos. Se tejen relaciones de poder en donde éste se ejerce y no se posee. La pugna por el poder siempre es reversible.

El poder no es un fenómeno de dominación masiva y homogénea de un individuo sobre los otros, de un grupo sobre otros, de una clase sobre otras; el poder contemplado desde cerca no es algo dividido entre quienes lo poseen y los que no lo tienen y lo soportan. El poder tiene que ser analizado como algo que no funciona sino en cadena. No está nunca localizado aquí o allá, no está nunca en manos de algunos. El poder funciona, se ejercita a través de una organización reticular.Y en sus redes circulan los individuos quienes están siempre en situaciones de sufrir o ejercitar ese poder, no son nunca el blanco inerte o consistente del poder ni son siempre los elementos de conexión. El poder transita transversalmente, no está quieto en los individuos (Foucault, 1984, p. 9). 
Los gitanos encontraron en el flamenco una forma de amparo ante la violencia de formas de opresión. Una forma de tomarse el poder.Y el quejío es la expresión de ese desarraigo y de la violencia que han padecido.

Los gitanos, que viven en la precariedad, que han sido excluidos, perseguidos, exiliados, exterminados, desterrados (“desplazados" o "desaparecidos", diríamos hoy en Colombia), olvidados, invisibilizados... esos gitanos marginados, que han vivido con el miedo en el cuerpo a ser encarcelados, esclavizados o simplemente, expulsados y asesinados, encontraron en el cante y el baile una forma de paliar la soledad, la injusticia, la falta de solidaridad, el racismo. Esos cuerpos, que en términos de Foucault fueron sometidos a la disciplina para la optimización de sus capacidades y al incremento de su utilidad, encontraron una forma de burlar ese poder, una forma de ser nuevamente visibles en una sociedad que los ha querido anular.

Podríamos expresar el sentido del quejío en términos de Foucault, retomando el concepto de las "prácticas de sí". Foucault las define de la siguiente manera:

Las prácticas sensatas y voluntarias por las que los hombres no sólo se fijan reglas de conducta, sino que buscan transformarse a sí mismos, modificarse en su ser singular y hacer de su vida una obra que presenta ciertos valores estéticos y responde a ciertos criterios de estilo.

(Foucault, 1984, p. 9).

El cuerpo de los gitanos escapa al control. Modo de afirmación y autoafirmación, fuerza emancipadora, el flamenco se volvió un arma contra la hostilidad y el desprecio. El cante y baile se volvieron armas contra la muerte. Estrategias pacíficas de supervivencia y resistencia, donde la voluntad de poder, de poder hacer y poder crear surgieron como alternativas a la ira reprimida y a una reacción violenta ante los agravios. Una transgresión que surge de la emoción.

La visión occidental del mundo ha sido construida sobre el paradigma de una sociedad blanca, masculina e ilustrada, como dice Vicent Martínez (Martínez, 2000). Aquellos cuerpos que no se ajustan a estos parámetros pasan de inmediato a una zona implacable de "irreconocimiento" social. A través del flamenco, los gitanos revierten ese orden, a través de acciones racionales que constituyen una experiencia subjetivada de sus vivencias y pasiones. Lo que proponen los gitanos a través del flamenco es una estética de la existencia basada en otros paradigmas de poder. Como dice Foucault, se vuelven empresarios de sí.

A manera de cierre, haremos nuestras las palabras de Didi-Huberman, cuando afirma que "se baila casi siempre para estar juntos" (Didi-Huberman, 2008). A través de la danza el duelo se vive más tranquilo, a través del flamenco llenamos eso que nosotros, en otras esferas, hemos llamado la presencia de la ausencia. 


\section{Notas}

${ }^{1}$ Estudiante del Doctorado Historia y Arte, Universidad de Granada, España (Director de la investigación: Doctor Isidro López-Aparicio) atocade@gmail.com

${ }^{2}$ En todos estos casos, ha sido definido sólo el género; las coreografías específicas están en proceso de selección.

${ }^{3}$ El 23 de septiembre de 2015 se firmó en La Habana, en el marco de las conversaciones para la paz en Colombia entre el gobierno y las Farc, el acuerdo sobre el capítulo llamado "Justicia Transicional", considerado clave en el avance del proceso. En él, es muy fuerte el acento puesto en la verdad como piedra angular de la justicia que ha de aplicarse.

${ }^{4}$ Los ejemplos abundan: Museo Historia del Holocausto en Jerusalén, Memorial de la Shoah en Paris, Museo de la Memoria y la Tolerancia de México, el Parque Monumento a las víctimas de Trujillo, Museo Memorial de la paz en Hiroshima, Museo Casa de la Memoria en Medellín, Museo de la Memoria en Buenos Aires...

5 “(...) they have a common value in forming 'an alternative voice or resistance to the dominant and dominating voices of violence". Traducción de la autora.

${ }^{6}$ Ese procedimiento sería propio del discurso sociológico, del histórico, del científico, de las ciencias sociales, del informativo - discursos cuya premisa fundamental es el reconocimiento explícito, factual, a un referente-

${ }^{7}$ http://lema.rae.es/drae/?val=gitano, consultado el 24/04/15, los énfasis son nuestros. Real Academia

Española (2001). Diccionario. Recuperado de http://lema.rae.es/drae/?val=gitano

\section{Referencias}

Córnago Ó. (Coord.) (2011). A veces me pregunto por qué sigo bailando. Madrid: Editorial Continta me tienes.

Didi-Huberman, G. (2008). El bailaor de soledades. En Dolores Aguilera (Trad.). Valencia: Pre-Textos. Foucault, M. (1981). Historia de la sexualidad.Vol. 1: La voluntad de saber. México: Siglo XXI Editores. (1984). Historia de la sexualidad 2. El uso de los placeres. México: Siglo XXI Editores.

García Lorca, F. (1998). Poema del cante jondo. En L. García Lorca de los Ríos (Coord.). Granada, España: Editorial Comares/ Fundación Federico García Lorca.

(2010). Juego y teoría del duende. Barcelona: Nortesur. (Trabajo original publicado entre 1928 y 1933).

Fernández, B. (2011). Restos. En Ó. Córnago (Coord.), A veces me pregunto por qué sigo bailando (pp. 49-53). Madrid: Editorial Continta me tienes.

Piñar Díaz, M. (2012). Cante flamenco, entre el duende y el quejío. Andalucía: QVE.

Martín, J. D. (2006). Jondo. Barcelona: Barataria.

Martínez, V. (septiembre-diciembre, 2000). Saber hacer las paces. Epistemología de los estudios para la Paz. Revista Convergencia, año 7, $N^{\circ} 23$, 49-96. Universidad Autónoma del Estado de México. Toluca, México.

Merleau-Ponty, M. (1964). Lo visible y lo invisible. Barcelona: Editorial Seix Barral.

Neville, E. (2006). Flamenco y cante jondo. Madrid: Rey Lear Editores.

Real Academia Española (2001). Diccionario. Recuperado de http:/ / lema.rae.es/drae/?val=gitano

Ramsbotham, O., Miall, H.\&, Woodhouse, T.(2011). "Conflict Resolution in Art and Popular Culture”, en Contemporary Conflict Resolution. Polity Press: United Kingdom.

Yoors, J. (2009). Los gitanos. En María José Aubet (Trad.). Barcelona: Bellaterra. (Trabajo original publicado en 1987).

Recibido: octubre 30 / Aprobado: noviembre 23 de 2015 